\title{
Seed and soil transmission of downy mildew (Perofascia lepidii) in seed producing garden cress
}

\author{
R. Djalali Farahani-Kofoet $\mathbb{B} \cdot$ R. Duensing • \\ F. Brändle • R. Grosch
}

Received: 6 February 2020 / Accepted: 28 April 2020 /Published online: 14 May 2020

(C) The Author(s) 2020

\begin{abstract}
Downy mildew on garden cress caused by Perofascia lepidii has become prevalent in organic seed producing areas of Germany resulting in limited seed production and high yield losses. Downy mildew occurrence in young plants in fields that have never been cultivated with garden cress raised questions about infested seeds and soils as sources of the primary inoculum and the role of other members of the plant family Brassicaceae as hosts of $P$. lepidii. To address these questions 31 seed lots from nine garden cress fields were examined for contamination using $P$. lepidii species-specific PCR assays. DNA of $P$. lepidii was detected in 17 seed lots out of 31 . In bioassays no disease was observed on plants grown from infested seed lots but in a few plants grown from seeds. The significance of soilborne inoculum was investigated by assessing disease incidence in plants grown in soil samples. Garden cress with downy mildew symptoms were recorded when plants were grown in pathogen infested soil samples. The results show that $P$. lepidii is able to survive in the soil and can be a primary inoculum source for downy mildew disease. Oospores formed in infected plants underpin the role of these survival structures that get incorporated into soil after harvesting. In a host specificity-test none of the tested species Brassica juncea; Brassica napus; Brassica rapa subsp.
\end{abstract}

R. Djalali Farahani-Kofoet $(\bowtie) \cdot$ R. Grosch

Leibniz Institute of Vegetable and Ornamental Crops (IGZ) e.V., Plant-Microbe Systems, Theodor-Echtermeyer-Weg 1,

14979 Großbeeren, Germany

e-mail: kofoetr@igzev.de pekinensis; Brassica rapa silvestris; Raphanus sativus var. oleiformis; Raphanus sativus var. sativus; Sinapis alba; Sinapis nigra; Arabidopsis thaliana; Capsella bursa-pastoris; Cardamine pratense; Cardaria draba; Nasturtium officinale were infected by P. lepidii.

Key words Downy mildew · Perofascia lepidii . Lepidium sativum L. · Seed production · Primary inoculum $\cdot$ Soil contamination $\cdot$ Seed contamination

\section{Introduction}

Garden cress (Lepidium sativum L., Brassicaceae) is an annual herb widely cultivated under temperate climate conditions throughout the world like India, West Asia, North Africa, Europe and USA (Nuez and Hernández Bermejo 1994; Tadesse et al. 2018). Garden cress is consumed as seedlings in salads and as seeds rich of proteins, dietary fiber, omega-3 fatty acids, iron and other essential nutrients (Singh and Paswan 2017). The commercial production of garden cress seedlings (around 5-8 days after germination) marketed in small trays is mostly based on organic cultivation, and necessitates the supply of nearly 500 metric tons of seeds per year for specialized German companies (Nega et al.

\author{
R. Duensing \\ Ökoplant eV, Rodenhäuser Str. 12, 35102 Lohra, Germany \\ F. Brändle \\ IDENTXX GmbH, Maybachstraße 50, 70469 Stuttgart, Germany
}


2005). Therefore some German organic farmers have specialized in garden cress seed propagation on acreages of around 60 ha. According to farmers seed production of garden cress occurs once a year between the months of April and July and is adaptable to nearly all soil types. It is grown like grain and after harvest the crop residues are incorporated into soil.

Due to downy mildew occurrence during garden cress seed propagation, German organic farmers are faced with high yield losses whereas seedling production in trays is not affected by this disease (Ulrich 2008). Typical symptoms of downy mildew of garden cress, caused by the obligate biotroph oomycete Perofascia lepidii (McAlpine) Constant. are yellow spots on the upper side and white down comprising sporangiophores on the underside of the leaves (Constantinescu and Fatehi 2002; Soylu et al. 2017; Djalali et al. 2018). At advanced disease stages also the upper side of the leaves, stems, flowering shoots, inflorescence and seedpods are covered with whitish down. In the field, downy mildew disease on garden cress plants was first noted at the rosette stage and diseased plants were often stunted and showed distorted growth (Ulrich 2008). Initially, the disease occurred in patches in the field, and was spread during the growth period (Ulrich 2008). Contrary to Constantinescu and Fatehi (2002) who asserted no economic damage through attacked and stunted organs, Ulrich (2008) declared high economically relevant yield loss due to the high disease severity at flowering and pod-formation stages where seed production was hampered. Mandal et al. (2008) reported on the occurrence of downy mildew on garden cress in India for the first time, and predicted increasing disease incidence since cultivation of garden cress is widely popular even in dry regions and is spreading in India. The pathogen is detectable via a species-specific PCR assay in infested plant tissues (Soylu et al. 2017; Djalali et al. 2018) and is known to produce oospores in examined garden cress tissue specimens (Constantinescu and Fatehi 2002; Soylu et al. 2017).

So far, there exist no studies on the life cycle of $P$. lepidii including survival strategies in garden cress seeds and soils. The occurrence of downy mildew during seed production in farms that were in geographically distant locations where no garden cress was grown before leads to the hypothesis that $P$. lepidii can be transmitted by seeds as attested for Peronospora effusa of spinach (Inaba et al. 1983), Peronoscleospora sorghi of maize (Adenle and Cardwell 2000) and Peronospora belbahrii of basil (Belbahri et al. 2005). Secondly, the question arises whether soils originating from garden cress seed producing areas are infested with $P$. lepidii and play a role as potential inoculum source as reported for other downy mildew pathogens like Peronospora viciae f. sp. pisi on pea (Van der Gaag and Frinking 1997), Pe. arborescens on poppy (Montes-Borrego et al. 2009), Plasmopara viticola on grape (Rossi and Caffi 2012) and Pseudoperonospora cubensis on cucumber (Zhang et al. 2012).

Downy mildew pathogens generally display high host specificity to one plant genus, but in some cases their host range also comprises various plants of a family. Hyaloperonospora, for example, causes downy mildew disease on Brassicaceae including economically relevant crops such as broccoli, cabbage, radish, and rape (Lee et al. 2017; Choi et al. 2017; Thines et al. 2009). Such hosts can also act as inoculum source through distribution of spores or contamination of soils with oospores. Currently, the known host range of $P$. lepidii is restricted to the host species Lepidium sativum, L. meyenii and L. viriginicum (Constantinescu and Fatehi 2002; Choi et al. 2017; Lee et al. 2017).

The aim of this study was to determine, for the first time, the potential of infested seeds and soils as sources of primary inoculum of $P$. lepidii including investigations on oospore formation in plant tissue and the role of other Brassicaceae members as host for P. lepidii.

\section{Material and methods}

\section{Garden cress seed batches}

Garden cress seeds were obtained from five different German field sites in Thuringia (NO = Nottleben), South Hesse (BS = Bad Schwalbach, ST = Steckenroth) and Central Hesse (SE = Seelbach, MI = Michelbach) (Table 1) where garden cress ('Cressida') was organically grown for seed propagation. Seed samples were randomly taken from plots of $1 \mathrm{~m}^{2}$ over the fields. The number of plots per field site varied between three and eight depending on the field size. Downy mildew occurrence was assessed for all sites during the growing period and in the preceding years. Disease incidence was monitored by estimating downy mildew occurrence on garden cress plants during the growing period (Table 1). At harvest time seeds were manually collected from each plot representing one seed batch. From the 
five field sites a total of 24 seed batches were received comprising 13-45 g seeds (average mass of 1000 seeds $=2.1 \mathrm{~g}$ ) depending on the yield (Table 1). In addition, contamination of seeds with $P$. lepidii was also tested in six seed batches taken randomly from commercially distributed seeds (distributor: Bingenheimer Saatgut, Germany). The seeds originated from organic production in Saxony (A/1, A/2), Thuringia (B), Bavaria (C), South Hesse (D) and a conventional producer in Thuringia (E) (Table 1). In addition, seed contamination was also tested for seeds obtained from a field trial where garden cress plants were artificially inoculated with a P. lepidii isolate (GB, Table 1).

For the PCR tests and bioassay the availability of healthy seeds as a control ( $\mathrm{Co}=$ control) had to be ensured. Seed samples originating from healthy plants of a field site (Nottleben, Thuringia - Germany) were used to subsequently produce seeds. These seeds were sown in pots (Ø $26 \mathrm{~cm}, 7.5 \mathrm{~L}, 6$ seeds per pot) and the plants were grown under greenhouse conditions until seed production. Continuous monitoring and preventive fungicide treatments with metalaxyl served as control measures to avoid any occurrence of downy mildew disease. Samples of these seeds (5 x 1000 seeds) were tested for contamination with P. lepidii via PCR (see below). No contamination was observed; hence these obtained seeds were used as the not-infested control (healthy seeds) in all tests.

Detecting Perofascia lepidii in garden cress seeds via end-point PCR

For detecting $P$. lepidii contamination in seed samples 2 $\mathrm{x} 1000$ seeds taken randomly from each of the seed batches (Table 1) including self-produced healthy seed samples (Co) were examined using a PCR approach. As template DNA extract from a $P$. lepidii spore solution $\left(10^{5}\right.$ spores $\left.\mathrm{ml}^{-1}\right)$ served as positive control and a PCR reagent with sterile water as negative control. Homogenization of seed samples (1000 seeds in $50 \mathrm{ml}$ Falcon tubes with added gravel to facilitate homogenization) was performed by FastPrep-24 (MP BIOMEDICALS, USA). After adding the lysis buffer of the DNA Plant Kit (PerkinElmer Technology GmbH, Germany) to the seed sample the homogenate was centrifuged for $5 \mathrm{~min}$ (4000 rpm, Thermo Scientific, USA) and the supernatant was used for DNA extraction. The specific primer pair (P.f-f, 5'-ACAGCCATTAGCCGATGGTTTGAA3'; P.f-r, 5'-TCCTGACACTAACTCAGCTTCCGC-3') was used for detection of $P$. lepidii. These sequences target, respectively, nucleotides 73-96 and 571-548 of GenBank accession DQ361181.1, which is a fragment of the coding sequence of a mitochondrial gene encoding NADH dehydrogenase subunit 1 (Göker et al. 2007). Detection of P. lepidii was performed following the protocol described by Djalali et al. (2018). The two DNA extractions (from 1000 seeds) were assessed separately and in case of detection of pathogen DNA at least in one extract the seed sample was rated as contaminated with $P$. lepidii.

Additionally, the presence of $P$. lepidii DNA in garden cress plant tissues of seed batches (A/1, A/2, B, C, D and $\mathrm{E}$, Table 1) was tested. These plants were cultivated in the growth chamber to assess the disease outbreak depending on seed contamination (see bioassay below). DNA was extracted from the stem basis (pieces of $4 \mathrm{~cm}$ long) of five plants per seed batch and pooled for DNA extraction. Plants grown from healthy seeds served as control. The detection of $P$. lepidii was done as described by Djalali et al. (2018).

Bioassay to assess seeds-to-seedlings transfer of downy mildew

The following bioassay was used for assessing garden cress seeds as primary inoculum source for downy mildew occurrence. Garden cress seeds were sown in pots (one seed per pot, $\varnothing 9 \mathrm{~cm}, 180 \mathrm{~mL}$ or six seeds per pot, $\varnothing 11 \mathrm{~cm}, 500 \mathrm{~mL}$ ) containing a volcanic clay and peat soil mixture ['Fruhstorfer Einheitserde Typ P', Havita; Germany; chemical analysis (mg per $100 \mathrm{~g}$ ): $\mathrm{N}=75$, $\mathrm{P}=75, \mathrm{~K}=125 ; \mathrm{pH}$ 5.9]. After germination the seedlings were subsequently grown until the flowering stage in growth chambers (York, Mannheim, Germany) at 20/ $15^{\circ} \mathrm{C}$ day-/night-cycle of $16 / 8$ hours, $60-70 \%$ humidity and a light intensity of $400 \mu \mathrm{mol} \mathrm{m} \mathrm{m}^{-2}$ since these conditions were determined as favorable for plant and disease development (Djalali et al. 2018). Plants were watered as required and fertilized twice a week with complete fertilizer $\left(\mathrm{Ca}\left(\mathrm{NO}_{3}\right)_{2}: 11.6 \mathrm{~g} ; \mathrm{KNO}_{3}: 9.6 \mathrm{~g}\right.$; $\mathrm{KH}_{2} \mathrm{PO}_{4}: 3.4 \mathrm{~g}, \mathrm{~K}_{2} \mathrm{SO}_{4}: 2 \mathrm{~g} ; \mathrm{MgSO}_{4}: 4 \mathrm{~g}$ per $100 \mathrm{~mL}$; pH: 5.8). Seeds randomly taken from each seed batch (NO, BS, SE, MI, ST, GB Table 1) were either sown singly (total of 405 seeds) or six seeds together (total of 432 seeds) in pots and grown under described conditions in growth chambers. Each treatment (seed batch) included three replicates with five pots each (one seed per pot) or three replicates with three pots each $(6$ seeds 
Table 1. Available seed batches sampled from nine German sites where garden cress seeds were produced organically (except for E) including the experimental station IGZ (Leibniz-Institut für Gemüse- und Zierpflanzenbau - Germany) with data on downy mildew disease incidence (DI) in selected plots. Seed batches A to
E were sampled from commercially distributed seeds provided by the German organic seed distributor Bingenheimer Saatgut, Germany. Downy mildew occurrence in the fields was estimated by organic farmers with yes or no.

\begin{tabular}{|c|c|c|c|c|}
\hline Seed batches ${ }^{1}$ & Site & site identity & Geographic coordinates & Downy mildew DI in plots ${ }^{2}$ and disease occurrence in fields ${ }^{3}$ \\
\hline $\mathrm{NO} / 1$ & Thuringia & $\mathrm{NO}$ & $50^{\circ} 96^{\prime} \mathrm{N} 10^{\circ} 84^{\prime} \mathrm{E}$ & + \\
\hline $\mathrm{NO} / 2$ & Thuringia & $\mathrm{NO}$ & & + \\
\hline $\mathrm{NO} / 3$ & Thuringia & NO & & + \\
\hline $\mathrm{BS} / 1$ & South Hesse & $\mathrm{BS}$ & $50^{\circ} 10^{\prime} \mathrm{N} 8^{\circ} 07^{\prime} \mathrm{E}$ & +++ \\
\hline $\mathrm{BS} / 2$ & South Hesse & $\mathrm{BS}$ & & +++ \\
\hline $\mathrm{BS} / 3$ & South Hesse & $\mathrm{BS}$ & & +++ \\
\hline $\mathrm{SE} / 1$ & Central Hesse & SE & $50^{\circ} 74^{\prime} \mathrm{N} 8^{\circ} 63^{\prime} \mathrm{E}$ & +++ \\
\hline $\mathrm{SE} / 2$ & Central Hesse & SE & & +++ \\
\hline $\mathrm{SE} / 3$ & Central Hesse & SE & & +++ \\
\hline $\mathrm{SE} / 4$ & Central Hesse & SE & & +++ \\
\hline $\mathrm{SE} / 5$ & Central Hesse & SE & & +++ \\
\hline $\mathrm{MI} / 1$ & Central Hesse & MI & $50^{\circ} 80^{\prime} \mathrm{N} 8^{\circ} 72^{\prime} \mathrm{E}$ & +++ \\
\hline $\mathrm{MI} / 2$ & Central Hesse & MI & & +++ \\
\hline $\mathrm{MI} / 3$ & Central Hesse & MI & & +++ \\
\hline $\mathrm{MI} / 4$ & Central Hesse & MI & & +++ \\
\hline $\mathrm{MI} / 5$ & Central Hesse & MI & & +++ \\
\hline $\mathrm{MI} / 6$ & Central Hesse & MI & & +++ \\
\hline $\mathrm{MI} / 7$ & Central Hesse & MI & & +++ \\
\hline $\mathrm{MI} / 8$ & Central Hesse & MI & & +++ \\
\hline $\mathrm{ST} / 1$ & South Hesse & ST & $50^{\circ} 44^{\prime} \mathrm{N} 7^{\circ} 83^{\prime} \mathrm{E}$ & + \\
\hline $\mathrm{ST} / 2$ & South Hesse & ST & & + \\
\hline $\mathrm{ST} / 3$ & South Hesse & ST & & + \\
\hline $\mathrm{ST} / 4$ & South Hesse & $\mathrm{ST}$ & & + \\
\hline $\mathrm{ST} / 5$ & South Hesse & ST & & + \\
\hline GB & IGZ & GB & $52^{\circ} 33^{\prime} \mathrm{N} 13^{\circ} 22^{\prime} \mathrm{E}$ & +++ \\
\hline $\begin{array}{l}\text { A/1 } \\
\text { A/2 heat-treated }\end{array}$ & $\begin{array}{l}\text { Saxony } \\
\text { Saxony }\end{array}$ & & $51^{\circ} 30^{\prime} \mathrm{N} 12^{\circ} 50^{\prime} \mathrm{E}$ & $\begin{array}{l}\text { no } \\
\text { no }\end{array}$ \\
\hline $\mathrm{B}^{*}$ & Thuringia & $\mathrm{NO}$ & $50^{\circ} 96^{\prime} \mathrm{N} 10^{\circ} 84^{\prime} \mathrm{E}$ & yes \\
\hline $\mathrm{C}$ & Bavaria & & $50^{\circ} 02^{\prime} \mathrm{N} 10^{\circ} 94^{\prime} \mathrm{E}$ & no \\
\hline $\mathrm{D}^{*}$ & South Hesse & BS & $50^{\circ} 10^{\prime} \mathrm{N} 8^{\circ} 07^{\prime} \mathrm{E}$ & yes \\
\hline$E^{5}$ & Thuringia & & n.a. & n.a. \\
\hline
\end{tabular}

${ }^{1}$ Seed batch numbers refer to the site identity and the plot number. NO = Nottleben; $\mathrm{BS}=\mathrm{Bad}$ Schwalbach; ST $=\mathrm{Steckenroth}$; SE $=$ Seelbach; MI = Michelbach; GB = Grossbeeren - Germany. *Seed batches B and D originated respectively from Nottleben (NO) and Bad Schwalbach (BS). ${ }^{2}$ DI was estimated in the plots: scattered disease patches across the field + , heavy attack.$+++{ }^{3}$ Disease occurrence in fields where seed batches A, B, C, D, E originated were assessed as yes or no according to farmers. ${ }^{4}$ Seeds were treated with heat in order to eliminate pathogen spores according to the seed distributor. ${ }^{5}$ Seed batch E originated from a conventionally grown field; n.a.: data not available.

per pot). Added together 837 seeds per seed batch were tested in 35 sequential bioassays where pots were placed randomly in growth chambers. Healthy seeds ran as control in each test. Starting 7 days after sowing until 7 weeks of cultivation, plants were scrutinized twice a week for the appearance of downy mildew symptoms. Before disease assessment plants were incubated for $20 \mathrm{~h}$ with wetted plastic hoods to advance downy mildew sporulation on plants (in the case of contamination). The number of plants with downy mildew symptoms 
was recorded and the disease incidence was calculated as number of diseased plants / total plants $\mathrm{x} 100$. In one additional bioassay plants of the seed batches $\mathrm{A} / 1, \mathrm{~A} / 2$, $\mathrm{B}, \mathrm{C}, \mathrm{D}$ and $\mathrm{E}$ (Table 1) were assessed for downy mildew occurrence. Each treatment included three replicates with six pots each. Six seeds were sown in each pot (totally 108 seeds) placed randomly in three growth chambers. Disease occurrence was monitored twice a week until the flowering stage of garden cress.

Testing soil as a potential inoculum source of downy mildew

To test soil as inoculum source of $P$. lepidii soils from the five garden cress field sites NO, BS, SE, MI and ST with downy mildew history (Table 1) were collected and used for cultivation of garden cress in the bioassay. Per field site, three soil samples (roughly $1 \mathrm{~kg}$ per location) were taken from the upper soil horizon $(20-30 \mathrm{~cm})$ out of three randomly chosen locations and pooled to one sample per field site (total of five soil samples). These soil samples were then filled in pots $(\varnothing 9 \mathrm{~cm}, 180 \mathrm{~mL})$ in which three healthy garden cress seeds (generated as described above) were sown. Each treatment included four replicates with four pots per replicate arranged in a randomized complete block design. Pots filled with the clay and peat soil mixture 'Fruhstorfer Erde' served as control. Plants were grown under favorable conditions for disease development in growth chambers as described above (bioassay). Disease occurrence among plants was assessed three days per week after seedlings emerged. Before assessing disease incidence in pots, plants were kept wet for $20 \mathrm{~h}$ to advance downy mildew sporulation. Pots comprising diseased plants were recorded and immediately removed from the growth chamber in order to avoid spread of disease. The experiment was terminated 7 weeks after sowing at the flowering stage. The presence of $P$. lepidii in single symptomatic plants was assessed using PCR.

\section{Testing survival of $P$. lepidii in soil}

To trace back the residual potential of $P$. lepidii oospores in soils over years, soils were sampled from seven fields ( $5 \mathrm{~kg}$ from five positions per field; mixed) at one German site $\left(50^{\circ} 96^{\prime} \mathrm{N} 10^{\circ} 84^{\prime} \mathrm{E}\right)$ in 2012 . In these seven fields garden cress was grown for seed production under organic farming conditions from 2000 until 2008 at varying frequencies (Table 4). Additionally soil from a neighboring field without garden cress history was also included into this experiment as control 1 (Table 4). To examine whether the soil samples were infested with $P$. lepidii three healthy seeds were sown in pots filled with the soil samples according to the bioassay (see above). Each treatment (soil sample) included three replicates with four pots per replicate. Pots filled with the clay and peat soil mixture 'Fruhstorfer Erde' served as control 2. The presence of $P$. lepidii in single symptomatic plants was confirmed by PCR.

Oospore formation of $P$. lepidii in garden cress plant tissues

In previous examinations no oospores could be found in plant tissues that were inoculated with the single stem isolate P. lepidii SE 1-11. Therefore we simultaneously inoculated garden cress plants with $5 \mathrm{~mL}$ of $P$. lepidii isolate SE 1-11 and three other P. lepidii isolates (3 $\times 10^{5}$ frozen sporangia $\mathrm{mL}^{-1}$ ). Those were isolated from diseased plants of field sites in south Hesse (BS: BS-U-11) and central Hesse (SE: SE-4-11, MI: MI-2-3-11) and had been verified as $P$. lepidii by PCR. All isolates were maintained and proliferated in garden cress plants and stored at $-20^{\circ} \mathrm{C}$ before usage (Djalali et al. 2018). The inoculated plants were first grown under favored conditions for disease development (see above) and then grown in a greenhouse for three months until plants were senescent. Stems were cut in thin sections and then scrutinized using light microscopy (Zeiss Axioskop 2, Germany) to find oospores. Additionally, tissues with oospores were examined by means of PCR to detect pathogen DNA.

\section{Host specificity of $P$. lepidii}

To find out whether members of the Brassicaceae could act as $P$. lepidii hosts and thus might contribute to the survival and spread of downy mildew in garden cress reproduction fields, 13 Brassica species that have relevancy either as a crop or weed were tested as potential hosts for P. lepidii. The selected crop species in this experiment were Brassica juncea L.; Brassica napus L.; Brassica rapa L. subsp. pekinensis; Brassica rapa L. silvestris; Raphanus sativus L. var. oleiformis; Raphanus sativus L. var. sativus; Sinapis alba L. and Sinapis nigra L. Arabidopsis thaliana L.; Capsella bursa-pastoris L.; Cardamine pratense L.; Cardaria draba L.; Nasturtium officinale L. were included as brassicaceous weeds. Respectively four plants of each 
species were grown in pots (Ø $11 \mathrm{~cm}$, volume $500 \mathrm{~mL})$ filled with the clay and peat soil mixture 'Fruhstorfer Erde' and grown in growth chamber $\left(15-20^{\circ} \mathrm{C}, 60-70 \%\right.$ relative humidity) up to the four leaf stage. Plants were irrigated with complete fertilizer twice weekly. The inoculation procedure was to spray $5 \mathrm{~mL}$ of a suspension of the stem isolate SE 11-1 (3 x $10^{5}$ frozen sporangia per $\mathrm{mL}$ ) onto the four plants within each pot. The plants were then held in growth chambers in the dark at $20^{\circ} \mathrm{C}$ for $18 \mathrm{~h}$ at $100 \%$ relative humidity, achieved covering the plants in wetted plastic sheeting. The plants were subsequently maintained under a $16 \mathrm{~h}$ photoperiod $\left(20 / 15^{\circ} \mathrm{C}, 60 \% / 80 \%\right.$ relative humidity) provided by lamps emitting $400 \mu \mathrm{mol} \mathrm{m} \mathrm{m}^{-2} \mathrm{~s}^{-1}$. In order to induce sporulation plants at the six to ten leaf stage were covered with wetted plastic sheets at $20^{\circ} \mathrm{C}$ in the dark for $20 \mathrm{~h}$ to ensure $100 \%$ relative humidity. Each treatment included three replicates with four pots per replicate arranged randomly in a complete block design. Garden cress plants (L. sativum var. sativum) served as control in this experiment. Plants were assessed 21 days post inoculation. The experiment was performed twice.

\section{Results}

Detecting Perofascia lepidii in garden cress seeds via end-point PCR

A total of 31 seed samples from eight commercial field sites (NO+B, BS+D, SE, MI, ST, A/1+ A/2, C and E; Table 1) and one experimental site (GB, Table 1) were investigated for contamination of seeds with $P$. lepidii using PCR. DNA of $P$. lepidii was detected in 17 out of 31 investigated seed batches, including the artificially inoculated seed batch GB: NO/3; BS/1; BS/2; SE/1; SE/ 3; MI/1; MI/2; MI/3; MI/4; MI/7; ST/3; ST/4; ST/5; B; $\mathrm{D}$ and $\mathrm{E}$ (Table 2). P. lepidii was not detected on the remaining 14 seed batches (Table 2).

Within the tissue samples taken from plants at the flowering stage in one bioassay, P. lepidii DNA could be detected in tissue samples of seed batch C (Table 3 ). In tissue of control plants no P. lepidii DNA was detected.

Bioassay to assess seeds-to-seedlings transfer of downy mildew

In repeatedly conducted bioassays in growth chambers, no downy mildew symptoms were observed in any of the plants growing out of the 31 seed batches (Table 2).
Table 2. Detection of Perofascia lepidii by specific molecular approach (PCR) in garden cress seeds 'Cressida' (Table 1). Seedto-seedling transfer of downy mildew was tested in bioassays on 837 seeds per sample (NO; BS; SE; MI; ST; GB; abbreviations refer to Table 1) and 108 seeds per sample (A-E) by determining disease incidence (DI) in growth chambers until the flowering stage. Downy mildew contamination was detected via PCR on 2x1000 seeds per sample (assessed separately and in case of detection of pathogen DNA at least in one extract the seed sample was rated as contaminated with $P$. lepidii). Healthy seeds were included in the tests as control (Co).

\begin{tabular}{|c|c|c|}
\hline Seed batch & DI & P. lepidii DNA in seeds \\
\hline $\mathrm{NO} / 1$ & - & - \\
\hline $\mathrm{NO} / 2$ & - & - \\
\hline $\mathrm{NO} / 3$ & - & + \\
\hline $\mathrm{BS} / 1$ & - & + \\
\hline $\mathrm{BS} / 2$ & - & + \\
\hline $\mathrm{BS} / 3$ & - & - \\
\hline $\mathrm{SE} / 1$ & - & + \\
\hline $\mathrm{SE} / 2$ & - & - \\
\hline $\mathrm{SE} / 3$ & - & + \\
\hline $\mathrm{SE} / 4$ & - & - \\
\hline $\mathrm{SE} / 5$ & - & - \\
\hline $\mathrm{MI} / 1$ & - & + \\
\hline $\mathrm{MI} / 2$ & - & + \\
\hline $\mathrm{MI} / 3$ & - & + \\
\hline $\mathrm{MI} / 4$ & - & + \\
\hline $\mathrm{MI} / 5$ & - & - \\
\hline $\mathrm{MI} / 6$ & - & - \\
\hline $\mathrm{MI} / 7$ & - & + \\
\hline $\mathrm{MI} / 8$ & - & - \\
\hline $\mathrm{ST} / 1$ & - & - \\
\hline $\mathrm{ST} / 2$ & - & - \\
\hline $\mathrm{ST} / 3$ & - & + \\
\hline $\mathrm{ST} / 4$ & - & + \\
\hline $\mathrm{ST} / 5$ & - & + \\
\hline GB & - & + \\
\hline $\mathrm{A} / 1$ & - & - \\
\hline $\mathrm{A} / 2$ & - & - \\
\hline B & - & + \\
\hline $\mathrm{C}$ & - & - \\
\hline $\mathrm{D}$ & - & + \\
\hline E & - & + \\
\hline Co & - & - \\
\hline
\end{tabular}

no disease occurrence out of seeds/plants or no DNA detection on plants and in seeds = -; presence of DNA of $P$. lepidii on seeds $=+$ 
Table 3. Seed-to-seedling transfer of Perofascia lepidii in garden cress plants depending on seed contamination. Seed contamination was verified by a molecular approach (PCR). Disease occurrence (DI) was tested in growth chambers during plant growth. Healthy plants ran as control (Co). Contaminated seed batches were obtained from five field sites in Germany (Table 1). Presence of P. lepidii DNA was also tested in plant tissue on stems (ca. $4 \mathrm{~cm}$ ) of each seed batch including healthy plants $(\mathrm{Co})(\mathrm{n}=5$, pooled).

\begin{tabular}{|c|c|c|}
\hline Seed batch & DI & $\begin{array}{l}\text { P. lepidii DNA } \\
\text { in plant tissues }\end{array}$ \\
\hline
\end{tabular}

\begin{tabular}{lll}
\hline $\mathrm{A} / 1$ & - & - \\
$\mathrm{A} / 2$ & - & - \\
$\mathrm{B}$ & - & - \\
$\mathrm{C}$ & - & + \\
$\mathrm{D}$ & - & - \\
$\mathrm{E}$ & - & - \\
$\mathrm{Co}$ & - & - \\
\hline-
\end{tabular}

Testing soil as a potential inoculum source of downy mildew

The first symptoms on single garden cress plants were found 27 days after sowing (das) of healthy garden cress seeds in the following soil samples: BS (1 pot), SE (9 pots), MI (3 pots) and ST (1 pot) (Fig. 1). Typical symptoms of diseased plants were stunted and deformed shoots. Frequently side shoot formation in the stem base of young diseased plants (four leaf stage) was observed before any other symptoms (white downs) on leaves and stems were evident. These prematurely induced side shoots appeared stunted, swollen and bright green. The number of diseased plants in each treatment increased during the course of the experiment. The highest number of diseased plants grew out of the soil samples SE and MI (Fig. 2). Not all three plants in a pot showed symptoms. Mostly one or two and sometimes three diseased plants per pot were counted. The soil sample was assessed as contaminated when one diseased plant was recorded. Pots with detected diseased plant/s were removed before termination of the whole experiment to avoid any contamination risk. In the control pots filled with clay and peat mixture 'Fruhstorfer Erde' no diseased plants could be observed during the time course of the experiment. In PCR test $P$. lepidii DNA was detected in symptomatic plants.

Testing survival of $P$. lepidii in soil

Survival of $P$. lepidii in soils obtained from seven commercial fields from one German site was assessed in a growth chamber experiment. In this bioassay, plants diseased with $P$. lepidii were found in four soil samples from fields 3, 5, 6 and 7 (Table 4). The pathogen could not be detected in soil samples from fields 1, 2 and 4 (Table 4). The results of field 3 (downy mildew occurrence in 2006 and in a bioassay in 2012) point out that

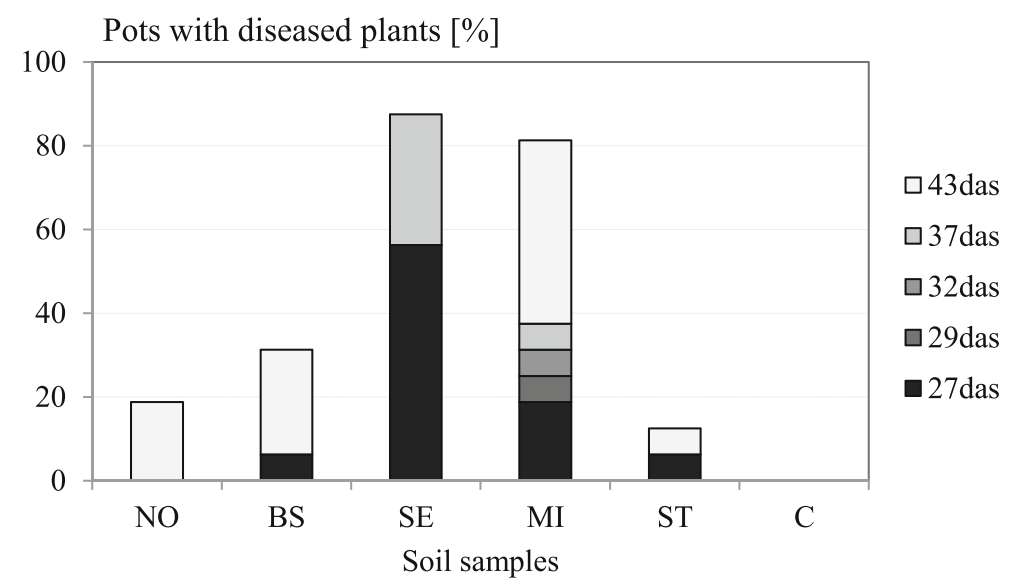

Fig. 1. Percentage of pots with garden cress plants (cv. Cressida) showing downy mildew symptoms caused by Perofascia lepidii. Healthy garden cress seeds were sown in soil samples and cultivated under controlled conditions. Soil samples were obtained from five commercial garden cress field sites [Thuringia (NO), south Hesse (BS, ST) and central Hesse (SE, MI), abbreviations refer to table 1] where the year before garden cress was cultivated for seed production. Disease occurrence in plants was assessed weekly beginning 6 days after sowing (das). Pots filled with uncontaminated clay and peat soil mixture ('Fruhstorfer Erde') served as the control (C). 
the pathogen is able to survive in soil for at least six years. No diseased plants could be observed in the control soils 1 and 2. P. lepidii DNA was detected in symptomatic plants by PCR.

Oospore formation of $P$. lepidii in garden cress plant tissues

Oospore formation was examined microscopically in leaves and stems of inoculated plants. Numerous oospores were observed on both leaves and stems of garden cress plants inoculated with the isolate P. lepidii SE 1-11 and the sporangia mix of the P. lepidii isolates BS-U-11, SE-4-11 and MI-2-3-11 (Fig. 2). By means of PCR P. lepidii DNA was detected in the plant tissues with oospores.

\section{Host specificity of $P$. lepidii}

Among the 13 tested Brassica species no plants showed any downy mildew symptoms 21 days post inoculation in contrast to garden cress plants with $100 \%$ disease incidence.

\section{Discussion}

According to German farmers, in the past ten years production of garden cress seeds in organic farms has increased due to the modest requirements of this fast growing culture. With this intensification, downy mildew disease in fields of garden cress seed production has spread dramatically and effective control measures are lacking (Ulrich 2008). Little is known about the biology including the primary inoculum source of the causative downy mildew pathogen $P$. lepidii in garden cress. So far it is unknown whether $P$. lepidii can be transmitted by seeds or if the pathogen is able to survive in soils as described for other downy mildew pathogens (Van der Gaag and Frinking 1997; Montes-Borrego et al. 2009; Rossi and Caffi 2012; Zhang et al. 2012). We assumed that both contaminated seeds and infested soils can act as primary inoculum sources for the occurrence of the downy mildew in garden cress and performed preliminary studies. Using a species-specific PCR assay to detect $P$. lepidii the presence of the pathogen was verified on seed samples harvested from diseased plants from eight commercial field sites of garden cress seed production plus seed samples obtained from our own
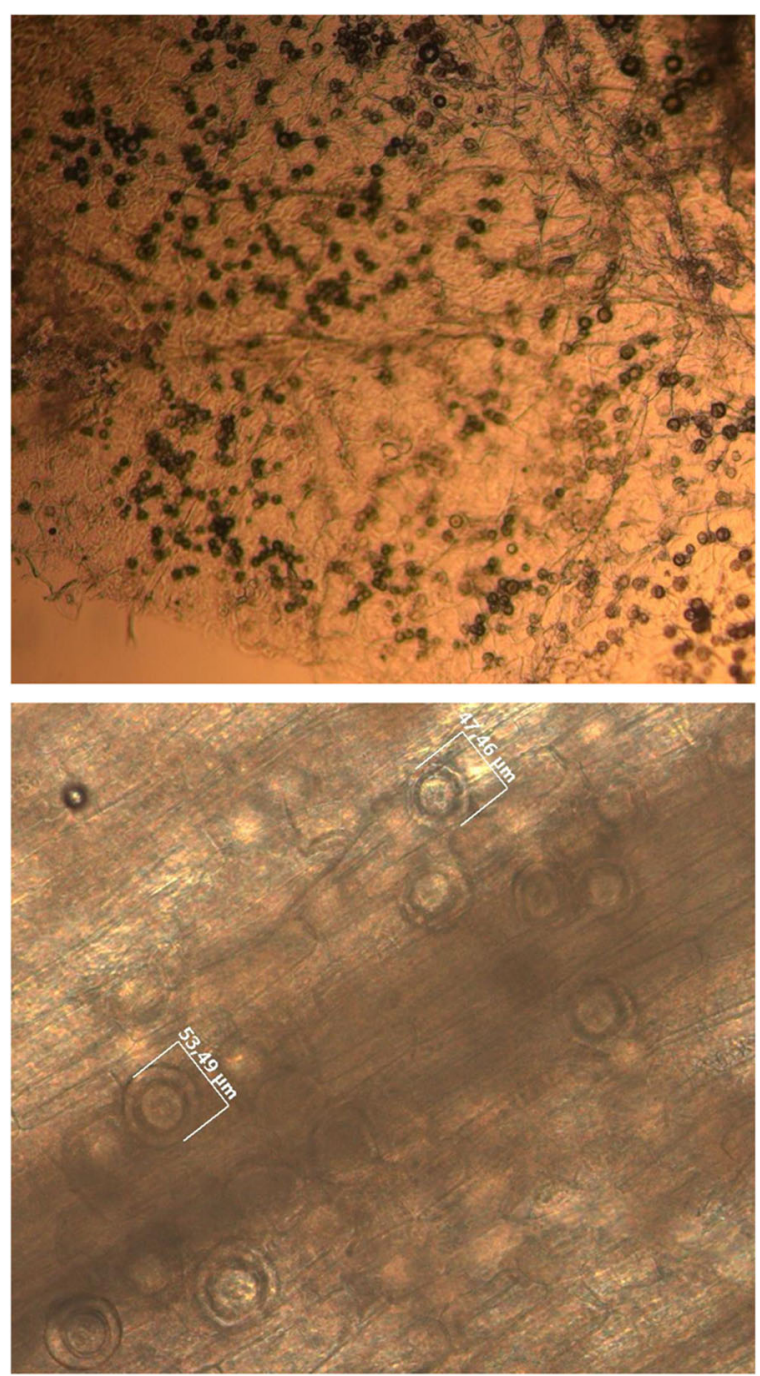

Fig. 2. Oospores of Perofascia lepidii abundant in (A) leaf (magnification 10x) and in (B) stem (magnification 20x) of garden cress (cv. Cressida) after being inoculated with a suspension mix of P. lepidii isolates (SE 1-11; BS-U-11; SE-4-11 and MI-2-3-11).

field experiment. Although we detected DNA of $P$. lepidii on seed samples of various seed batches by PCR, the proof that contaminated seeds give rise to plants with symptoms failed in all bioassays. No visible downy mildew symptoms were observed on plants grown from seeds associated with $P$. lepidii DNA in any of our bioassays. PCR tests are fast and accurate tests in finding the pathogen DNA, but the limitation of these tests lies in the lack of differentiation between living and dead material that could be adhered to the seeds. Pathogen DNA could be detected in tissues of plants of one seed batch (C) but not in control plants in a bioassay (Table 3 ). This result indicates that $P$. lepidii 
Table 4. Garden cress cultivation years and occurrence of downy mildew (DM) disease in seven organic fields before soil sampling. Soil samples were obtained from these fields in 2012 to test for the presence of Perofascia lepidii in soil using a bioassay performed under controlled conditions. Pots filled with soils originating from a neighboring field with no garden cress history (control soil 1) and the clay/peat soil mixture 'Fruhstorfer Erde' (control soil 2) served as control. First DM symptoms were assessed 35 days after sowing (das).

\begin{tabular}{|c|c|c|c|c|}
\hline \multirow{2}{*}{$\begin{array}{l}\text { Fields/soils } \\
1\end{array}$} & \multicolumn{3}{|c|}{$\begin{array}{l}\text { Garden cress cultivation } \\
\text { years and DM } \\
\text { occurrence* }\end{array}$} & \multirow{2}{*}{$\begin{array}{l}\text { DM occurrence in } \\
\text { bioassay } 35 \text { das }\end{array}$} \\
\hline & 2005: + & & & \\
\hline 2 & 2002: - & & & - \\
\hline 3 & 2000: - & 2006: ++ & & + \\
\hline 4 & 2003: - & $2007:++$ & & - \\
\hline 5 & 2003: - & 2007: ++ & & + \\
\hline 6 & 2003: - & 2004: + & 2008: ++ & + \\
\hline 7 & 2004: - & 2008: ++ & & + \\
\hline Control soil 1 & - & - & - & - \\
\hline Control soil 2 & - & - & - & - \\
\hline
\end{tabular}

$*_{-}=$no DM; + = scattered DM occurrence in patches in the field or DM symptoms in a bioassay; $++=$ high yield loss

can be transmitted by seeds. It was surprising that P. lepidii DNA could be detected in tissues of the associated plants of these seeds although the seed samples were assessed as free of $P$. lepidii DNA in the previous PCR assay. This fact underscores that for detection of pathogens in seed batches the amount of the sampled seeds is a common limiting factor. Asymptomatic downy mildew infected plants may lead to infected seed crops and subsequent crop infestations during favorable environmental conditions. In this study we didn't examine all plants growing out of tested seed batches to give proof of asymptomatic infection. A suitable sampling size is important to ensure statements on seed contamination and potential plant infestation. This should be considered in further research. Smith and Price (1997) reported that contamination of seeds with Hyaloperonospora parasitica could not be verified in grow out tests on Brassica oleracea cultivars under controlled and greenhouse conditions. However, low disease incidence was monitored in seed batches of other crops for example 0.2 to $8.8 \%$ for P. farinosa $\mathrm{f}$. sp. chenopodii in quinoa (Danielsen et al. 2004) or 1 to $15 \%$ for $H$. parasitica in radish (Jang and Safeeulla 1990). Achar (1995) found an infection rate of 0.3$6.9 \%$ in Brassica oleracea seedlings with
H. parasitica after sowing 1000 seeds in growth chamber. These observations and the results of this study suggest that seed batches are in general heterogeneously contaminated with the pathogen and that the contamination rate among seed batches varies, as is the case in this study.

Indeed, we have no evidence for the contamination level of the seed batches that were tested. At a low contamination rate randomly chosen seed samples were probably accidentally pathogen-free and it is uncertain whether the low frequency of seed transmission that is detectable can be confirmed in outgrowing tests in bioassays. It should be considered that the number of tested seeds (ca. 840) per seed batch was low in our experiments. Jang and Safeeulla (1990) recommend largescale experiments with large sample sizes of 10,000 seeds in order to detect a $0.1 \%$ embryo infection. This is also recommended by Smith and Price (1997). The tests in this study included at least 21,000 seeds in total but these were obtained from different seed batches and one can assume that the contamination rate of all of them was rather low.

The limited knowledge about the biology of $P$. lepidii, and especially about the conditions required for particular phases of pathogenesis such as sporulation could be a further reason for the lack of diseased plants in our bioassays. The important role of weather conditions such as temperature and relative humidity during pathogenesis may play a pivotal role for disease development. Therefore field experiments are recommended to examine seeds-to-seedling transfer of $P$. lepidii. On the other hand the conditions for disease development in growth chambers cannot be doubted since we were successful in rearing seedlings with downy mildew symptoms in the bioassays with soils. The results of these experiments highlight soil as a primary inoculum source for P. lepidii.

Finding of oospores in plant tissue of garden cress confirms the assumption that soils with high quantities of infested post-harvest crop residues can play a role as inoculum source for downy mildew occurrence in garden cress seed production. Oospores are important as survival units during host-free periods. This is proven for oospores of Peronospora viciae f. sp. pisi that survive in soil and act as a primary inoculum source in pea crops (Van der Gaag and Frinking 1997). Spring and Zipper (2000) considered oospores of Plasmopara halstedii as the primary and therefore most important source of infection for seedlings in early springtime. In 
our experiments the first downy mildew symptoms on garden cress plants growing in soil samples obtained from commercial fields with downy mildew history arose as soon as 27 days after sowing. The majority of infected plants grew out of the soil SE, which was perhaps infested with a higher inoculum density of P. lepidii than the other tested soil samples. Comparable with seed batches the inoculum density varied in tested soil samples. Therefore, we assume that the soil sample SE was highly contaminated with oospores of $P$. lepidii compared to the other tested soil samples. Moreover, it is important to note that all soil samples were taken randomly, so that no particular assessment concerning the contamination degree of soil can be made for one field. In future studies further attempts are needed to quantify the amount of inoculum and the viability of oospores to be able to estimate the disease occurrence in fields.

In addition, we aimed to obtain an indication of how long resting spores of $P$. lepidii can survive in soil. Therefore, we examined the survival of $P$. lepidii in soils of seven fields that were grown with garden cress over years by one organic farmer (in Thuringia, Germany). Garden cress has been grown in these fields since 2000 in rotation and the first occurrence of downy mildew was in 2005 in one field, and since then it has occurred in neighboring fields whenever garden cress was grown. The soil samples were collected in 2012 and survival of the pathogen was assessed in our bioassay. Soil samples from four fields (fields 3, 5, 6 and 7) indicated that P. lepidii can survive for several years (maybe at least six years as in field 3; downy mildew disease on garden cress occurred six years before) in the soil and act as a primary inoculum source in the next garden cress crop. However, symptoms were not observed in all fields. This fact can be attributed to the sample, since all of them were randomly taken from a field size of 20 ha. One must consider that diseased plants occur mainly in patches and the soil samples were taken randomly in 2012. The contamination of soil by oospores as a major inoculum source for a succeeding crop of susceptible species in the same field and the transfer of inoculum to other fields by wind, unspecific vectors or machines cannot be excluded. Hence, our results do not allow any conclusions about distinct survival times, which will also be affected by several environmental conditions such as microbial community structures in soil, crops included in crop rotation, or weather conditions. Nevertheless, our results highlight that the occurrence of downy mildew in garden cress cannot be controlled by crop rotation alone.

Oospores are the survival structure in soil after being produced in infected plant tissue, and released into soil as the plant tissue degrades. We therefore aimed to induce their formation in garden cress plants. Oomycete pathogens can be homothallic, heterothallic or both (Michelmore 1981). To accomplish sexual reproduction homothallic species are able to mate with themselves on the same thallus, whereas heterothallic species require two compatible mating partners. So far, little is known about sexual reproduction and mating of $P$. lepidii. In our approach, we wanted to confirm the production of oospores in plant tissue and therefore inoculated garden cress plants with several $P$. lepidii isolates originating from different contaminated soil samples. In previous examinations we couldn't find any oospores in plant tissues of plants that were inoculated by the isolate P. lepidii SE 1-11. Our results showed that a high number of oospores were found in stems and leaves of plants that were inoculated with four $P$. lepidii isolates at the same time. Based on this finding we can confirm the observations of Constantinescu and Fatehi (2002) that $P$. lepidii is able to form oospores. In our investigations P. lepidii SE 1-11 was not able to produce oospores in the plant tissue. This might be an indication that no oospores were formed from the same thallus, but more studies with single isolates and mating between two isolates are needed for reliable proof of heterothallism of $P$. lepidii. H. parasitica is reported to be both homothallic and heterothallic, and the likelihood of finding oospores was less when heterothallic strains were required for oospore production (Smith and Price 1997). Cohen and Rubin (2012) could find oospores in inoculated cucumber in in vitro test when pairs of Ps. cubensis isolates were mixed but not when they were inoculated singly. Thomas et al. (2017) found two mating types, A1 and A2 of Ps. cubensis in the United States and could only produce oospores by mating the two types. They attested the viability of produced oospores at nearly $40 \%$ and attributed them as playing an important role in the epidemiology of cucurbit downy mildew in the US. Oospore production is associated with chlorotic and necrotic host tissue in several downy mildew diseases. This has led to the suggestion that oospore formation is induced by senescence or necrosis of the host tissue (Michelmore 1981) as also observed in our study. Knowledge about the infection efficiency of the oospores in initiating epidemics in garden cress should 
be considered in further studies, as proposed for $P S$. cubensis by Thomas et al. (2017).

Cultivation of garden cress for seed proliferation takes place in fields next to other agricultural/ horticultural crops. To exclude cultures belonging to the Brassicaceae as hosts of $P$. lepidii, the susceptibility among a range of brassicaceous plants including vegetables, agricultural crops and also weeds that grow in fields was assessed. None of the tested plants were susceptible to $P$. lepidii, therefore we exclude crop species like Brassica juncea L.; Brassica napus L.; Brassica rapa L. subsp. pekinensis; Brassica rapa $\mathrm{L}$. silvestris; Raphanus sativus L. var. oleiformis; Raphanus sativus L. var. sativus; Sinapis alba L.; Sinapis nigra L. and the weeds Arabidopsis thaliana L.; Capsella bursa-pastoris L.; Cardamine pratense L.; Cardaria draba L.; Nasturtium officinale L. as hosts of $P$. lepidii. The results underline that $P$. lepidii seems to be host specific, as also observed for other downy mildew pathogens (such as Pe. belbahrii of basil and coleus, Ps. cubensis of cucumber, Pe. viciae f. sp. pisi of pea, $P$ e. arborescens of poppy and $P l$. viticola of grape) and that important brassicaceous plants can be excluded as inoculum source for garden cress downy mildew.

The results of this study verify that garden cress soil can act as primary inoculum source of $P$. lepidii in garden cress seed production and should be considered as a pivotal source for disease occurrence. The oomycete pathogen forms oospores in garden cress tissues, which are incorporated into soil after harvest, and these resting spores are able to survive in soil between growing seasons. One cannot exclude oospores adhering to the seeds as being responsible for disease transmission. However, it is difficult to evaluate the relative contribution of each inoculum source on yield reduction when both seed- and field-borne sources of inoculum are present. One can conclude that downy mildew epidemics in garden cress seed production can develop from single diseased plants. For $P$. lepidii there exist no information about the movement of the spores via air as it is intensely investigated for other downy mildews like Pseudoperonospora cubensis (Cohen 1981; Holmes et al. 2004) that is stated as a pivotal source for the epidemic dissemination of the pathogen in the crop and neighboring fields. Investigations on aerial dispersal of $P$. lepidii are very time consuming but need to be performed thoroughly in future research in areas where garden cress is grown for seed production. Knowledge about the inoculum sources of downy mildew in garden cress can support disease control possibly through chemical disinfestation or mechanical heat treatment. It is also important that farmers pursue precautionary measures in order to prevent contamination via mechanical vectors. Another possible but costly option is reducing soil contamination by removing crop residues from the field after harvest in case of disease occurrence during cultivation.

Acknowledgements The authors thank Sieglinde Widiger for her valuable technical practical assistance and colleagues at IGZ who helped with the horticultural work. The authors thank Bingenheimer Saaten, German garden cress farmers and Ökoplant for providing seed lots. This research was financially supported by a grant (2810OE116) from the German Federal Office for Agriculture and Food (BLE).

Funding Information Open Access funding provided by Projekt DEAL.

\section{Compliance with ethical standards}

Conflict of interest The authors declare that they have no conflict of interest.

Open Access This article is licensed under a Creative Commons Attribution 4.0 International License, which permits use, sharing, adaptation, distribution and reproduction in any medium or format, as long as you give appropriate credit to the original author(s) and the source, provide a link to the Creative Commons licence, and indicate if changes were made. The images or other third party material in this article are included in the article's Creative Commons licence, unless indicated otherwise in a credit line to the material. If material is not included in the article's Creative Commons licence and your intended use is not permitted by statutory regulation or exceeds the permitted use, you will need to obtain permission directly from the copyright holder. To view a copy of this licence, visit http://creativecommons.org/licenses/by/4.0/.

\section{References}

Achar, P. N. (1995). Tissue culture technique to determine the viability of Peronospora parasitica in Brassica oleracea. Journal of Phytopathology, 143, 647-649.

Adenle, V. O., \& Cardwell, K. F. (2000). Seed transmission of maize downy mildew (Peronosclerospora sorghi) in Nigeria. Plant Pathology, 49, 628-634.

Belbahri, L., Calmin, G., Pawlowski, J., \& Lefort, F. (2005). Phylogenetic analysis and real time PCR detection of a presumably undescribed Peronospora species on sweet basil and sage. Mycological Research, 109, 1276-1287.

Choi, Y.-J., Thines, M., Choi, A.-Y., \& Shin, H.-D. (2017). Perofascia is not monotypic: the description of the second 
taxon affecting the South American crop maca (Lepidium meyenii). Mycological Progress, 16, 857-864.

Cohen, Y. (1981). Downy mildew of cucurbits. In D. M. Spencer (Ed.), The downy mildews (pp. 341-354). Academic Press: New York.

Cohen, Y., \& Rubin, A. E. (2012). Mating type and sexual reproduction of Pseudoperonospora cubensis, the downy mildew agent of cucurbits. European Journal of Plant Pathology, 132, 577-592.

Constantinescu, O., \& Fatehi, J. (2002). Peronospora-like fungi (Chromista, Peronosporales) parasitic on Brassicaceae and related hosts. Nova Hedwigia, 74, 291-338.

Danielsen, S., Mercado, V. H., Ames, T., \& Munk, L. (2004). Seed transmission of downy mildew (Perosnospora farinosa f.sp. chenopodi) in quinoa and effect of relative humidity on seedling infection. Seed Science \& Technology, 32, 91-98.

Djalali, F.-K. R., Braendle, F., \& Grosch, R. (2018). Molecular characterisation of downy mildew caused by Perofascia lepidii on garden cress and conditions favouring disease development. Journal of Plant Diseases and Protection, 125, 491-500.

Göker, M., Voglmayr, H., Riethmüller, A., \& Oberwinkler, F. (2007). How do obligate parasites evolve? A multi-gene phylogenetic analysis of downy mildews. Fungal Genetics and Biology, 44, 105-122.

Holmes G.J., Main C.E., Keever Z.T. (2004). Cucurbit downy mildew: a unique pathosystem for disese forecsting. In Spencer-Phillips PTN, Jege M. (Eds.), Advances in Downy Mildew Research, Vol. 2 (pp 69-80). Dordrecht: Kluwer.

Inaba, T., Takahashi, K., \& Morinaka, T. (1983). Seed transmission of spinach downy mildew. Plant Disease, 67, 11391141.

Jang, P., \& Safeeulla, K. M. (1990). Modes of entry, establishment and seed transmission of Peronospora parasitica in radish. Proceedings of the Indian Academy of Sciences-Plant Sciences, 100, 369-373.

Lee, J. S., Lee, H. B., Shin, H.-D., \& Young-Joon Choi, Y.-J. (2017). Diversity, Phylogeny, and Host-Specialization of Hyaloperonospora Species in Korea. Mycobiology, 45, 139-149.

Mandal, K., Patel, P. R., \& Maiti, S. (2008). First report of downy mildew on Lepidium sativum in India. Australasian Plant Disease Notes, 3, 73-74.

Michelmore R.W. (1981). Sexual and asexual sporulation in the downy mildews. In D.M.Spencer (Ed.), The Downy mildews. Academic Press: London, New York.

Montes-Borrego, B., Landa, B. B., Naves-Cortés, J. A., MunozLedesma, F. J., \& Jiminez-Diaz, R. M. (2009). Role of oospores as primary inoculum for epidemics of downy mildew caused by Peronospora arborescens in opium poppy in Spain. Plant Pathology, 58, 1092-1103.

Nega, E., Lissek-Wolf, G., Werner, S., \& Jahn, M. (2005). Gesundes Kresse-Saatgut. Gemüse, 11, 20-21.
Nuez F., Hernández Bermejo, J.E. (1994). Neglected horticultural crops. In: Hernández Bermejo, J.E. and León J. (Eds.), Neglected Crops: 1492 from a different perspective. FAO Plant Production and Protection, Series No.26 (pp 307310). Food and Agriculture Organization of the United Nations: Rome.

Rossi V., Caffi T. (2012). The Role of Rain in Dispersal of the Primary Inoculum of Plasmopara viticola. Phytopathology, 102, 158-65

Singh S.C., Paswan V.K. (2017). The Potential of Garden Cress (Lepidium sativum L.). Seeds for Development of Functional Foods. https://doi.org/10.5772/intechopen.70355

Smith, P. A., \& Price, T. V. (1997). Preliminary study of seed transmission of downy mildew in some vegetable brassica cultivars in Australia. Australasian Plant Pathology, 26, 54 59.

Soylu, E. M., Kara, M., Kurt, S., Uysal, A., Shin, H. D., Choi, Y. J., \& Soylu, S. (2017). First report of downy mildew disease caused by Perofascia lepidii on garden cress Lepidium sativum in Turkey. Plant Disease, 101, 1827.

Spring, O., \& Zipper, R. (2000). Isolation of oospores of sunflower downy mildew, Plasmopara halstedii, and microscopical studies on oospore germination. Journal of Phytopathology, 148, 227-231.

Tadesse, L., Mekbib, F., Wakjira, A., \& Tadele, Z. (2018). Correlation and path coefficient analysis of yield and quality components of garden cress (Lepidium sativum L.) genotypes in Ethiopia. Journal of Plant Breeding and Crop Science, 10, 290-297.

Thines M., Voglmayr H., Göker M. (2009). Taxonomy and phylogeny of the downy mildews (Peronosporaceae). In: Lamour K. and Kamoun S. (Eds.), Oomycetes and Genomics: Diversity, Interactoins, and Research Tools (pp 47-75). John Wiley \& Sons Inc. 2009, https://doi.org/10.1002 /9780470475898.ch3.

Thomas, A., Carbone, I., Cohen, Y., \& Ojiambo, P. S. (2017). Occurrence and distribution of mating types of Pseudoperonospora cubensis in the United States. Phytopathology, 107, 313-321.

Ulrich, R. (2008). Falscher Mehltau (Perofascia lepidii) an Kresse-Samenträgern. Gemüse, 7, 57.

Van Der Gaag, D. J., \& Frinking, H. D. (1997). Survival characteristics of oospore populations of Peronospora viciae f. sp. pisi in soil. Plant Pathology, 46, 978-988.

Zhang, Y., Pu, Z., Zhou, X., Liu, D., Dai, L., \& Wang, W. (2012). A study on the overwintering of cucumber downy mildew oospores in China. Journal of Phytopathology, 160, 469474.

Publisher's note Springer Nature remains neutral with regard to jurisdictional claims in published maps and institutional affiliations. 